International Journal of Quality \& Reliability Management

emerald PUBLISHING

International Journal of Quality \& Reliability Management

A customer journey perspective on service delivery system design: insights from healthcare

\begin{tabular}{|r|l|}
\hline Journal: & International Journal of Quality \& Reliability Management \\
\hline Manuscript ID & IJQRM-03-2018-0073.R1 \\
\hline Manuscript Type: & Quality Paper \\
\hline Keywords: & $\begin{array}{l}\text { Service delivery system, service quality, customer experience, service } \\
\text { design }\end{array}$ \\
\hline Abstract: & \\
\hline \multicolumn{2}{|c}{} \\
\hline
\end{tabular}

$$
\begin{gathered}
\text { SCHOLARONE }^{m} \\
\text { Manuscripts }
\end{gathered}
$$

http://mc.manuscriptcentral.com/ijgrm 


\section{A customer journey perspective on service delivery system design: insights from healthcare}

\section{Abstract \\ Purpose}

The purpose of this paper is to provide novel theoretical insight into service delivery system (SDS) design. To do so, this paper adopts a customer journey perspective, using it as a frame to explore dimensions of experience quality that inform design requirements.

\section{Methodology}

This study utilises UK Patient Opinion data to analyse the stories of 200 cancer patients. Using a critical incident technique, 1,207 attributes of experience quality are generated and classified into 17 quality dimensions across five stages of the customer (patient) journey.

\section{Findings}

Analysis reveals both similarity and difference in dimensions of experience quality across the patient journey: seven dimensions are common to all five journey stages, from receiving diagnosis to end of life care; ten dimensions were found to vary, present in one or several of the stages but not in all.

\section{Limitations}

Limitations include a lack of representativity of the story sample and the impossibility to verify the factual occurrence of the stories.

\section{Practical implications}

Adopting a patient journey perspective can improve practitioner understanding of the design requirements of SDS in healthcare. The results of the study can be applied by managers to configure SDS that achieve higher quality of patient care throughout the patient journey.

\section{Originality/value}


This paper extends existing literature on SDS design by adopting a customer journey perspective, revealing heterogeneity in experience quality across the customer journey currently unaccounted for in SDS design frameworks. Specifically, the findings challenge homogeneity in extant SDS design frameworks, evidencing the need for multiple, stagespecific SDS design requirements.

\section{Keywords}

Service delivery system, service quality, customer experience, service design

\section{Research Paper}




\section{INTRODUCTION}

The role of the patient experience in evaluating the quality of care and for driving operational improvement is now explicitly taken into account in numerous countries such as Australia, Canada, Denmark, France, Germany, Japan, Italy, the Netherlands, New-Zealand, Norway, Switzerland, Turkey, the United Kingdom (UK) and the USA among others (Black and Jenkinson, 2009; Garratt et al., 2008). In the UK, for instance, it is clearly articulated in the National Health Service (NHS) Constitution for England $\left(27^{\text {th }}\right.$ July 2015) that, alongside clinical effectiveness and patient safety, patient experience is intrinsic to inform the design of systems that provide high quality care. Policy development over the last decade has been informed by a growing intensity of patient experience research (for example, Goodrich and Cornwell, 2008) and prominent reports (Lord Darzi, 2008). The salience of patient experience was most notably brought to public attention during inquiries into failings at North Staffordshire NHS Trust (Francis, 2013).

As medical science continues to make substantial advances in improving treatments, similar effort is required by researchers to inform the design of service delivery systems (SDS) that support the provision of patient experiences (Danaher and Gallan, 2016). Previous studies have indicated that the quality of a patient experience not only affects satisfaction and loyalty behaviours (Russell et al., 2015; Dagger et al., 2007), but also impacts clinical effectiveness, overall well-being, and quality of life (Ryan et al., 2014; Ponsignon et al., 2015b). There is evidence that understanding the patient experience represents a significant opportunity for articulating the design requirements of SDS in healthcare (Francis, 2013; Baig et al., 2014). Despite a growing intensity of research: the incorporation of patient experience into the NHS Outcomes Framework (2013/14); the development of experienceoriented performance indicators in the NHS Outcomes Framework (2014/15); the identification of specific quality statements to guide practice (NICE, 2012) - the question of 
how to design the healthcare SDS for the provision of successful patient experiences remains underdeveloped. This emphasises the need to provide an understanding of patient experiences to inform SDS design.

The customer (patient) experience describes an individual's cognitive, affective and sensory evaluation of a series of interactions with a provider's SDS (Johnston and Kong, 2011). As customers experience multiple interactions with an organisation at different points in time (Kranzbühler et al., 2017), the customer journey is an important unit of analysis (Rawson et al., 2013; Tax et al., 2013). Marketing scholars conceptualise the customer journey in three generic high-level stages: pre-purchase, purchase and post-purchase (Lemon \& Verhoef, 2016). In a recent review of extant customer experience research Lemon and Verhoef (2016, p.82) note that "multiple practice-oriented authors have stressed the importance of customer experience management across touch points". This resonates with Homburg et al. (2017) who emphasise that firms should build the capability to design the customer journey across multiple stages. From this theoretical perspective, SDS design is concerned with the configuration of operational resources and processes to support the realisation of a successful experience at all stages and points of customer contact (Pullman and Gross, 2004). However, Voss et al. (2008 p.252) argue that the predominant perspective of extant work in SDS design focuses on the service provider's perspective "with the aim of making the delivery system more efficient". The origin of this perspective can be attributed to the production management antecedents of the discipline (Sampson and Froehle, 2006; Machuca et al., 2007).

The present study responds to explicit calls for operations management (OM) research to break away from a provider-centric tradition, focused on maximising operations efficiency, and to focus instead on the design of SDS that create positive customer experiences (Voss et al., 2008; Roth and Menor, 2003; Ponsignon et al., 2015a; Zomerdijk and Voss, 2010). 
Specifically, it aims to develop an understanding of the customer (patient) journey

perspective to inform SDS design requirements in a healthcare context. Moreover, an analysis of a customer-centric perspective of SDS affords comparisons with existing, provider-centric theoretical frameworks and provides opportunities for intellectual development. This study's research question is formulated as: how do experience quality dimensions effect SDS design requirements across the patient journey?

Our empirical research extends extant theory on the design of SDS in a healthcare context through the identification customer centric quality attributes representing the important dimensions of the patient experience across multiple journey stages. We identify both core and stage-specific dimensions that vary in importance over the course of the patient journey. These dimensions are reconciled with design characteristics, found in extant theory, and provide three intellectual insights. First, we identify that core design characteristics, common to all stages of the patient journey, correspond with both a service focus and a cost focus. We therefore find evidence in support of the inadequacy of homogenous assumptions, prevalent in extant SDS design frameworks, which advocate holistic design configuration based on proximity to the cost-service dichotomy (Johansson and Olhager, 2004; Metters and Vargas, 2000; Contiero et al., 2016). Second, despite the consistency of core dimensions across stages, clear differences in their relative importance are reported. In addition, the analysis of stage-specific attributes reveals key differences across stages, indicating that patient priorities change at different points in the healthcare journey. Importantly, SDS design models, as emphasised in contingency studies and classification schemes (Roth and Menor, 2003; Cook et al., 1999; Ponsignon et al., 2011; Safizadeh et al., 2003), do not distinguish between the individual stages of the customer journey, and therefore overlook the specific design requirements of individual stages. This evidence indicates the incompleteness of existing theoretical frameworks and suggests the need for significant revision to account for 
multiple, stage-specific SDS design requirements. Third, we identify several stage specific dimensions that do not reconcile with design characteristics found in provider-centric design frameworks. The evidence suggests that adopting a customer-centric perspective provides a finer-grained and more precise specification of design requirements that should be incorporated into SDS frameworks.

To provide this evidence base we adopt four research design principles. First, we explore design requirements from a customer (patient) perspective. Second, we focus on identifying dimensions of customer experience quality that inform design requirements for the service provider. Third, building on Sampson (2012) we investigate the mode of interaction between provider and customer (Direct, Indirect, Independent). Fourth, we focus on the customer journey to establish contextual conditions; allowing the identification of similarity and difference in the dimensions found across journey stages and the mode of interaction present.

\section{THEORETICAL BACKGROUND}

\section{Service Delivery System Design}

Three streams of OM literature contribute to our understanding of SDS design. First, service classification frameworks identify categories of SDS that share similar operational characteristics and specify design, control and improvement challenges (Collier and Meyer, 1998; Silvestro, 1999). These frameworks provide valuable insights into the design requirements for different SDS (Verma and Thompson, 1999) by articulating configurations of relevant design characteristics (Safizadeh et al., 2003). Second, established contingency models such as the Service Strategy Triad (Roth and Menor, 2003) and subsequent empirical studies (Ponsignon et al., 2011; Contiero et al., 2016) emphasise that SDS design choices are contingent on strategy or on the service concept. The service concept "embodies the totality 
of the service elements that are either important to target customers or are purchased by them" and drives the implementation of SDS design characteristics (Roth and Menor, 2003). Typically, OM research has focused on articulating the design requirements of SDS from the provider's perspective, based on the planned service concept (Voss et al., 2008), which specifies the attributes that the organisation regard as important for the customer. For instance, Ponsignon et al. (2011) empirically examine the attributes of a large utility company's four main service concepts and explore the design characteristics of the four corresponding processes that support these service concepts. Third, recent OM literature emphasises the need to establish SDS design that supports the attainment of superior customer experiences (Voss et al., 2008; Stuart and Tax, 2004; Roth and Menor, 2003). Conceptual and empirical studies emphasise the customer journey as an important unit of analysis (Lemon and Verhoef, 2016; Rawson et al., 2013) in pursuit of customer experience. The customer journey represents the entire process of all individual interactions between the customer and the organisation. The journey concept is typically broken down into three generic high-level stages: pre-purchase, purchase and postpurchase (Lemon and Verhoef, 2016). Previous studies identify salient issues in customer experience and explore how firms: structure the customer journey using a stage-based approach; analyse and improve underperforming stages; and position peak events at the beginning and the end of the customer journey (Zomerdijk and Voss, 2010; Ponsignon et al., 2015a).

Extant service classifications and contingency models emphasise a dichotomous design choice that is typically aligned with a cost or service focus (Johansson and Olhager, 2004; Metters and Vargas, 2000; Ponsignon et al., 2011; Silvestro, 1999). The objective of cost-focused SDS design is to provide standardised service concepts and achieve levels of efficiency in the operation. Design characteristics commonly associated with efficiency are: low employee skills, low employee discretion, low customisation, high automation, 
equipment-focus, centralised location and high formality (Johansson and Olhager, 2004;

Cook et al., 1999). Service-focused SDS design provides customised solutions and seeks flexibility to accommodate variety in customer request and response (Frei, 2007). The characteristics of these designs include: high employee skills, high employee discretion, high customisation, low automation, people-focus, distributed locations and low formality. These studies do not account for the journey-based nature of the customer experience to conceptualise SDS design (Helkkula, 2011; Lemon and Verhoef, 2016; Kranzbühler et al., 2017). As a result, they emphasise a static perspective of the SDS as design characteristics are assumed to transcend all customer interactions taking place over the course of the customer journey. Additionally, they assume homogeneity in the holistic design configuration associated with cost-focused and service-focused SDS. Since the customer's experience of the SDS involves a multiplicity of interactions at different stages (Lemon and Verhoef, 2016), there is the need to explore SDS design requirements along the entire customer journey, from needs recognition to needs fulfilment.

\section{Recent OM studies in a healthcare context}

Several recent studies have explored the design and improvement of healthcare operations (Rich and Piercy, 2013). These studies typically pursue the objective of improving process efficiency through the optimisation of patient flows and resource utilisation (Russell et al., 2015). For example, Drupsteen et al. (2013) examine how cooperation between the various members of an internal supply chain helps to improve patient flows. Wang et al. (2009) propose a simulation model to identify process bottlenecks and resource allocation to reduce waiting time in emergency services. Henrique et al. (2016) apply value stream mapping to identify operational bottlenecks and waste that impact patient treatment time. Vissers et al. (2001) present a conceptual framework for achieving a balance between service and 
efficiency goals in hospitals. They articulate how planning and control decisions affect patient flows and resource utilisation.

There has, however, been growing recognition that the patient is an important factor to consider for SDS design and improvement (WHO, 2016; van Schoten et al., 2016). Patient centricity is increasingly engendered in a number of quality management initiatives found in healthcare contexts (Lagrosen et al., 2007; Ho Voon et al., 2014). Specifically, customer (patient) focus is a core principle of quality management theory (Anderson et al., 1994), and an important prerequisite for the development of a service excellence culture in hospitals (Ho Voon et al., 2014; Russell et al., 2015). This emphasises the need to pay attention to the patient's perspective of SDS design. The impetus of this perspective is to articulate requirements for the provision of high quality healthcare services (Russell et al., 2015; Ho Voon et al., 2014).

\section{The role of quality attributes in informing SDS design}

A distinction is made between the 'planned' service concept, which corresponds to the provider's view of what matters to customers, and the 'realised' service concept, which refers to the customer's evaluation of his or her actual experience (Roth and Menor, 2003). This customer-centric perspective resonates with previous research on quality function deployment (Dijkstra and van der Bij, 2002; Sousa et al., 2016) which suggests that designing the SDS from the patient's perspective involves capturing patient-perceived quality attributes and translating them into design requirements. A customer-centric perspective on SDS design therefore involves exploring how customers evaluate their interactions with the SDS and how this unfolds over the course of the customer journey.

Service quality research is broadly concerned with understanding and capturing people's perceived judgments about their interactions with a SDS (Prakash and Mohanty, 
2013). Understanding the patient's perceptions of their actual experience, by highlighting what is important to them, helps to determine the characteristics the SDS should exhibit to drive patient satisfaction. Previous research has revealed a range of themes that SDS should emphasise: relational quality reflects how patients perceive their interactions with staff members; administrative quality represents issues related to timeliness, operational services and support services; technical quality involves the medical outcomes achieved and the provider's skills and knowledge; environment quality captures patient perceptions of tangible elements and the atmosphere they create (Dagger et al., 2007).

While research on service quality in healthcare is extensive (Russell et al., 2015), most studies emphasise a narrow conceptualisation and static measurement of service quality (Prakash and Mohanty, 2013; Kranzbühler et al., 2017) that omits to acknowledge that the patient experience consists of a journey that takes place over multiple stages (Danaher and Gallan, 2016). Extant research tends to focus on customers' perceptions about a specific healthcare interaction, or about interactions taking place within a particular healthcare facility or practice (Manary et al., 2013; Russell et al., 2015), rather than the patient experience as a whole. For instance, Dagger et al. (2007) focus on service quality perceptions in an outpatient clinic; Fottler et al. (2006) explore patient perceptions of customer service in a hospital; Gruber and Frugone (2011) study the quality of interactions between patients and general practitioners after a service failure; Russell et al. (2015) focus on multiple clinic types, medical specialties and physician types in evaluating the factors affecting patients' perceptions of quality of care; Wisniewski and Wisniewski (2005) investigate service quality dimensions in a colposcopy clinic. Building on service quality research, the nascent experience quality literature take a more holistic approach to conceptualise perceived healthcare quality. While Ponsignon et al. (2015b) empirically develop a comprehensive 
framework for experience quality in a healthcare context that extends health service quality models, no attempt is made to distinguish between the stages of the patient journey.

Recent evidence indicates that the patient experience usually involves a series of distinct episodes to get diagnosed, treated and cared for (Lee et al., 2013). Tsianakas et al. (2012) focus on the experience of cancer patients and observe that different issues emerge at each part of the journey. For instance, patients emphasise the importance of communicating diagnosis results sensitively and of receiving immediate post-diagnosis support. In contrast, the expertise and friendliness of staff are salient features of the experience of inpatients. This suggests that patient perceptions and priorities change at different stages of the patient journey. The assumed homogeneity found in the SDS literature would, therefore, be unable to accommodate these changing requirements. As these stages collectively form a complete experience from the patient's perspective, SDS design must be informed by patient perceptions at each stage of the journey. It is only from a complete journey perspective that a holistic set of requirements can be determined to inform SDS design.

\section{Customer-oriented approaches for SDS design}

The OM literature emphasises the need to establish SDS design that supports the attainment of superior customer (patient) experiences (Voss et al., 2008; Stuart and Tax, 2004; Roth and Menor, 2003). In pursuit of this goal several methods and techniques to understand and visualise SDS from the customer's perspective have been reported (Sampson, 2012). These techniques focus on representing the activities customers perform in the process of service delivery, and the interactions taking place between the organisation and the customer (Bitner et al., 2008). An interesting conceptualisation (Sampson, 2012) found in this extant work is the mode of interaction that occurs in service delivery. Specifically, this work suggests that service provision involves: a direct (interpersonal) interaction between people; an indirect 
interaction between customer (patient) and facilities and/or systems; an independent activity disconnected from the delivery system. This distinction is important because each mode of interaction has unique design implications (Sampson, 2012). However, while the techniques presented in extant literature promote the need to understand, and to take account of, patient activity to inform SDS design (Prakash and Mohanty, 2013), they do not offer explicit characteristics or requirements for SDS design; particularly those dependent on the context of the stage of the patient journey.

In summary, current intellectual frameworks concerning the design of SDS are predominantly determined from a provider's perspective. The design choices presented by these frameworks are dichotomous, contingent on strategy or the service concept and assumes design characteristics that transcend all customer interactions within the SDS. Recent research has emphasised the customer journey as an important unit of analysis. The multiple stages comprising a journey potentially provide a useful perspective to determine design characteristics under specific contextual conditions. To explore this phenomenon an empirical study is undertaken to identify dimensions of experience quality, representing the realised service concept, from a patient perspective. A healthcare context provides the opportunity to investigate the totality of interactions that comprise the patient journey. To classify, and differentiate between, experience quality dimensions we identify modes of interaction (direct, indirect, and independent) that can help inform design requirements for each contextual stage. The study is therefore designed to explore similarity and difference in experience quality dimensions and corresponding design characteristics both within, and across stages of the customer journey. We therefore formulate our research question as:

How do experience quality dimensions effect SDS design requirements across the patient journey? 


\section{RESEARCH METHODOLOGY}

\section{Source of data}

Numerous online platforms that encourage patients to express their opinions about their healthcare experiences have emerged worldwide. These novel data sources provide valuable insights into the performance of healthcare SDS from the patient's perspective (Greaves et $a l ., 2013$ ). Patient Opinion (PO) is the leading independent patient feedback platform in the UK with in excess of 40,000 stories at the time of the study. PO aims to elicit the key aspects of patient experiences by asking patients to answer several simple questions including "What is your story about?" and "What happened?" The increasingly important role played by PO in understanding, evaluating and improving healthcare services was explicitly recognised in a major government-sponsored report (Francis, 2013). Unlimited access to the PO database was granted by PO's Head of Research, following exposition of the research objectives by the research team.

\section{Rationale for using natural language stories}

Stories captured in the PO database provide a significant opportunity for capturing the patient journey and revealing the important attributes of healthcare services from the patient's perspective. Bate and Robert (2006) argue that understanding the patient experience requires gaining 'access to the knowledge acquired from close or direct observation or contact and expressed in what a person thinks, feels and says about the experience' (p.309). They add that an experience is best analysed 'indirectly through the words and languages people use to describe it when they look back at it' (p.308) and that stories 'contain almost everything ... required for a deep appreciative understanding of the strengths and weaknesses of a present service' (p.309). 


\section{Background information on the UK National Health Service}

The UK NHS was founded in 1946 and has now become one of the largest healthcare systems in the world, with circa 1.5 million staff employed by the NHS. Since its inception, this publicly funded healthcare system has been governed by two principles: the NHS is free of charge at the point of use and available to all permanent residents, based on need and not ability to pay. The NHS operates in a broadly similar way to other health systems in that it is split up into two main divisions: the first division is responsible for strategy, policy and management, and the other deals with the provision of actual medical and clinical care (Grosios et al., 2010). The latter includes primary care (e.g. general practitioners, dentists and pharmacists), secondary care (e.g. hospitals) and tertiary care (e.g. specialist hospitals). Like other national healthcare systems, predictive, preventive and personalised services are part of disease diagnosis and treatment. For instance, the NHS Choices website (https://www.nhs.uk/), which recorded 583 million visits in 2015, describes how patients can obtain personalised advice in relation to their condition, and offers information on predictive tests for disease such as diabetes (Grosios et al., 2010). Recently, the patient experience concept has come to the fore with the incorporation of patient experience and the development of experience-oriented performance indicators into the NHS Outcomes Framework (2014/15) as well as with the identification of specific quality statements to guide practice (NICE, 2012).

\section{Sample selection and characteristics}

We focus on stories of cancer patients because cancers are long-term acute conditions involving several phases of treatment and care over an extended period of time. Additionally, previous research shows that patients suffering from different types of cancer describe similar journeys of care (Tsianakas et al., 2012). Focusing on this single condition allows sufficient homogeneity in the sample to derive evidence-based quality dimensions over common 
journey stages. We extracted the entire set of cancer patient stories $(\mathrm{N}=1552)$ that were available in the PO database. Following the arguments of adequate sample size in previous studies (RCN, 2013), a sample of 200 stories was randomly selected. To be included in the sample, a story had to describe the healthcare experience of a cancer patient and needed to be sufficiently detailed and comprehensible to allow the capture of experience quality attributes. Where abrupt and overly succinct patient feedback was identified (at the initial screening stage) the story was removed from the sample and replaced with an additional randomly selected story. The average length of a story was 288 words. The sample covered a diversity of time periods, UK regions and cancer types.

\section{Data analysis}

We used the critical incident technique (CIT) to build a patient journey model and to develop categories of experience quality attributes. CIT affords an objective, systematic and generalizable analysis of communication content (Gremler, 2004). CIT is commonly used in research where the objective is to elicit attributes of customer attitudes and behaviours (Ulbrich et al., 2011; Stanworth, 2012). The analysis was carried out in three main phases (i.e. coding, category development and category validation) following typical CIT guidelines (Gremler, 2004; Keaveney, 1995). The unit of analysis was therefore identified as a story (critical incident) containing experience quality attributes. A quality attribute reflects a patient's self-reported cognitive, affective or sensory evaluation of any direct, indirect or independent interaction with the SDS.

In phase one, two researchers independently coded the 200 stories in the NVivo

software for qualitative analysis to identify the main stages of the patient journey and to reveal the attributes of the patient experience. Coding the stories independently contributes to maximizing analytical rigour and achieving a shared understanding of the data. Each 
independent analysis was subsequently compared to identify inconsistencies in the coding and to pursue consensus. Data saturation (Bowen, 2008) was reached toward the end of the coding process as no new quality attributes were found. In total, 1,207 attributes were generated and sorted into five distinct journey stages. Finally, the researchers organized the identified experience quality attributes using the mode of interaction advocated by Sampson (2012): direct interactions (834); indirect interactions (332), and independent activities (41) .

The second phase involved sorting the attributes into categories that represent experience quality dimensions. The coded data was divided into two halves. A development sample contained 558 attributes relating to the Inpatient Care stage. A verification sample of the remaining items afforded the opportunity to test the emerging framework. The two coders from phase one became judges A and B. They independently sorted and classified the development sample into categories following a two-step process of inductive and deductive logic. The first step (inductive logic) focused on developing and defining provisional, mutually-exclusive, categories based on similarities and differences in the experience quality attributes. The second step (deductive logic) focused on examining the provisional categories against service quality and service classification frameworks (Dagger et al., 2007; Lemke et al., 2011; Cook et al., 1999; Johansson and Olhager, 2004) to maximise consistency with extant theory. After sorting all of the attributes into mutually-exclusive categories, reliability rates were computed (Gremler, 2004) and classification inconsistencies resolved by discussion. A third researcher, Judge C, sorted and classified the attributes into the developed categories. Inter-judge reliability rates indicated a significant degree of agreement between Judge C's decisions and the first two judges' classification. Overall, an average reliability rate of $87.3 \%$ on the Perreau and Leigh's (1989) index was achieved for the first sample of data items. 
In the third phase, the classification process was repeated on the verification sample. Several new categories were created, suggesting that some quality attributes appear elsewhere in the patient journey than at the Inpatient Care stage. The average inter-judge reliability rate for the second sample of items was $89.4 \%$ on the Perreau and Leigh (1989) index.

\section{FINDINGS}

\section{Patient journey stages}

Data analysis revealed 1,207 attributes spread across five distinct journey stages in the sample of 200 stories (Table 1); indicating the multiple stages of care reported by individual informants.

\section{$<$ Please insert Table 1 about here $>$}

The results indicate, for each stage, the number of experience attributes found (n) and the percentage of the 200 story sample they were found in (s), presented as $(\mathrm{n} / \mathrm{s})$. Receive Diagnosis $(223 / 30 \%)$ relates to the interactions and activities leading to the assessment and communication of a patient's condition. Inpatient Care (558/54\%) includes the patient's admission to the healthcare facility, treatment, overnight stay and discharge. Outpatient Care (221/28\%) describes situations where a patient visits a healthcare facility for treatment but does not stay overnight. Post-Treatment Care (73/17\%) refers to the experience of follow-up healthcare services including check-ups, aftercare, medical support and complaint handling. End-of-Life Care (132/11\%) refers to the support provided to terminally-ill patients. While the results indicate a dominance of feedback relating to the Inpatient Care stage, it is clear that the sample provides data on all patient journey stages, and therefore permits a detailed exploration of experience quality across these stages. 


\section{Experience quality dimensions}

The 1,207 attributes were classified into 17 categories representing patient-centric experience quality dimensions. The nature of the interaction (Direct/Indirect/Independent) was also indicated (Sampson, 2012). Table 2 defines these dimensions.

$<$ Please insert Table 2 about here $>$

Our analysis reveals both similarity and difference between (and across) the stages of the patient journey. Similarity is found in seven dimensions that are common to all journey stages, as shown in Table 3. Specific quality dimensions, pertinent to particular stages, are also identified.

\section{$<$ Please insert Table 3 about here $>$}

Within the group of 'direct interactions', four common experience quality dimensions are identified across the entire journey. The number of attributes (n) of each dimension found in the sample (s) is reported in Table 4 and described below (n/s): attitudes and behaviours (480/79.5\%); personalisation (105/41\%); communication $(101 / 39.5 \%)$; staff competence (89/33\%). In addition, common experience quality dimensions, across all journey stages, can be found in the 'indirect' mode of interaction: premises and facilities $(101 / 28.5 \%)$; procedures and processes (96/29\%); indirect communication (61/21.5\%). While these experience quality dimensions are common to all stages their intensity per stage is seen to vary. This variance can be seen in Table 3. Prominent common dimensions together with dimensions that are stage-specific are discussed for each stage of the patient journey below.

$<$ Please insert Table 4 about here $>$

Receive Diagnosis

18 
Prominent common (direct interaction) experience quality dimensions found in this stage are: attitude and behaviour (64/47\%); communication (26/33\%); competence (20/30\%). Prominent (indirect interaction) dimensions are reported as: procedures and processes (18/25\%). Stage specific dimensions include: timeliness (independent activity) (19/25\%); speed (independent activity) (11/18\%); timeliness (indirect) (8/13\%); staff efficiency (direct) $(7 / 12 \%)$. This stage requires highly competent staff, good communication skills and a sensitive attitude. This would correspond with accurate diagnosis and sensitive communication of results. In addition, it is clear that the overall efficiency of the diagnosis and subsequent communication are both important requirements for this stage.

\section{Inpatient Care}

Experience quality dimensions (direct interaction) include: attitude and behaviour (240/73\%); personalisation (47/36\%); communication (44/35\%); competence (40/26\%). For indirect interactions, premises and facilities (55/29\%) and procedures and processes (42/29\%) are important. We note the need to consider the atmosphere of the SDS including levels of noise, temperature and smell that can affect the patient experience. Stage specific dimensions for this stage include: food and beverage (indirect interaction) (29/21\%); staff availability (direct interaction) (21/19\%); relationship with patients (direct interaction) 18/15\%). Inpatient Care clearly requires a SDS that incorporates all the common experience quality dimensions. Additionally, the data reveals that both the diversity and suitability of food and beverage is important for this stage. Specifically, this involves ensuring that food and drink is appropriate given specific medical conditions. Furthermore, the impact of direct interactions among patients needs to be accommodated when designing systems for this stage. This includes, for example, preserving privacy or creating a sense of unity/community. 


\section{Outpatient Care}

Two common experience quality dimensions are particularly important in the Outpatient Care stage: attitudes and behaviours (95/67\%); direct communication (17/27\%). Interestingly, accessibility (indirect interaction) $(22 / 31 \%)$ is an important design consideration for this stage. Accessibility refers to the ease of finding and accessing the healthcare premises and facilities. As in the case of Receive Diagnosis, experience quality dimensions relating to efficiency are identified. Timeliness (independent activity) (5/11\%) relates to judgments about the reliability of appointment times when patients are on the healthcare premises. In contrast, timeliness (indirect interaction) (12/22\%) highlights patients' perceptions of waiting for an appointment date, test or operation. This stage therefore requires a delivery system that emphasises interpersonal characteristics, accessibility, and efficiency.

\section{Post-Treatment Care:}

Two prominent common experience quality dimensions are identified in this stage. A direct interaction, attitudes and behaviour (17/32\%), and an indirect interaction, procedures and processes $(16 / 38 \%)$. As in the case of Receive Diagnosis and Outpatient Care stages, timeliness (independent activity) (6/12\%) is identified in the patient-centric data. An additional dimension, continuity of care (direct interaction) $(4 / 12 \%)$ is also identified. It should be noted that only $17 \%$ of stories, within the total sample, identified the PostTreatment Care stage. This was significantly lower than any other stage in the analysis. While there is relatively limited data, the experience quality dimensions identified suggest a SDS combining interpersonal characteristics combined with efficiency. It is interesting to observe the emphasis on both continuity of care and procedures and processes. This may suggest that the design of the SDS, at this stage, needs to account for both interpersonal/attitudinal 
requirements, while at the same time addressing standardisation/routines through standard operating procedures.

\section{End-of-Life Care}

The experience quality dimensions found within End-of-Life Care exhibit similarity to the Inpatient Care stage. Six of the seven common dimensions are important. Direct interactions include: attitudes and behaviours (64/91\%); communication (10/36\%); personalisation (18/59\%); competence (6/27\%). Indirect interactions include: premises and facilities $(9 / 32 \%)$; procedures and processes $(9 / 32 \%)$. These common dimensions suggest that SDS design must allow for personalisation and customisation through accommodating attitudes and behaviours and high levels of staff competence. Furthermore, it suggests the need for standardised processes and procedures. Three further stage specific (direct) experience quality dimensions are also identified: staff availability (4/18\%); relationship with other patients (5/18\%). Again, this exhibits similarity with Inpatient Care, where issues of patient community or privacy need to be addressed. One final dimension identified is service variety/choice (3/14\%). It is clear that in an end-of-life context customisation, personalisation and the provision of a range of service choices shapes perceptions of experience quality.

\section{DISCUSSION}

\section{Implications for theory}

The results of this study provide some important intellectual insights into the design of SDS. We identify dimensions of customer (patient) experience quality across multiple journey stages that inform design requirements for the service provider. These dimensions are reconciled with design characteristics found in SDS design frameworks in Table 5. Articulating SDS design requirements from a customer-centric perspective provides 21 
comparatively increased specificity than established (provider-centric) frameworks such as contingency models and classification schemes (Roth and Menor, 2003; Voss et al., 2008) found in extant OM literature. We identify three distinct contributions that this research makes to this extant literature.

First, our customer-centric analysis illuminates homogenous (core) requirements across the journey stages. We provide evidence that each stage is associated with a similar set of core dimensions, albeit differing in relative importance. Specifically, four common experience quality dimensions were found with a direct mode of interaction (Sampson, 2012): attitudes and behaviours; communication; personalisation; competence. Three further dimensions, with an indirect mode of interaction were also common across all stages: premises and facilities; procedures and processes; communication. The evidence base (Table 3) reveals that each stage is associated with core dimensions that are representative of both cost-focused and service-focused SDS. For example, the 'personalisation', 'competence' and 'direct communication' dimensions, which are defining characteristics of service-oriented SDS (Johansson and Olhager, 2004; Ponsignon et al., 2011), account for more than $20 \%$ of patient feedback at each stage. Similarly, the 'procedures and processes' dimension, which is primarily emphasised in cost-oriented SDS (Ponsignon et al., 2011; Contiero et al., 2016; Silvestro, 1999), is consistently important across all stages. We therefore find evidence in support of the inadequacy of homogenous assumptions, prevalent in extant SDS design frameworks, which advocate holistic design configuration based on proximity to the costservice dichotomy. This empirical evidence provides an extension to the extant literature's assumption that the design characteristics associated with either a cost-oriented or a serviceoriented perspective are appropriate across all stages of a customer journey. It highlights the need for customer-centric SDS design frameworks that accommodate multi-stage SDS with 
heterogeneous service and cost focused requirements and corresponding design characteristics.

Second, despite the consistency of these core dimensions across stages, clear differences in their relative importance are reported (see Table 3). In addition, the analysis of stage-specific attributes reveals further major differences across stages. This evidence suggests that patient priorities change at different points in the healthcare journey. For instance, patients require swift diagnosis by competent and caring healthcare professionals and rapid communication of results ('receive diagnosis' stage). In contrast, the ability of staff to communicate effectively with patients, provide personalised care that accommodates specific needs, in a quality physical and social environment are strongly emphasised by inpatients ('inpatient care' stage). The increased specificity achieved by the present study therefore emphasises different design requirements across the stages of the patient journey. From the customer's perspective, each individual stage needs to be carefully designed according to its unique requirements. This supports and extends the generic customer journey model of Lemon and Verhoef (2016) as well as the work of Tsianakas et al. (2012), who identified that different issues shape the cancer patient experience at three stages (i.e. diagnosis, inpatient, moving through the system). This suggests that organisations, in pursuit of providing a high-quality customer experience, must pay specific attention to these stage specific design requirements. This is consistent with work in the broader literature (Rawson et al., 2013; Zomerdijk and Voss, 2010) that has identified the importance of a customer journey focus. The evidence also suggests that SDS design models, as emphasised in contingency studies and classification schemes, require extension. These frameworks do not distinguish between the individual stages of the customer journey and overlook potential changes in what customers value at different stages of the process. This suggests that attempting to provide a superior experience with a system-wide design is likely to constrain 
performance from the customer's perspective. Existing models need to be expanded to account for multiple, stage-specific SDS designs. A journey-orientation takes into account any direct, indirect or independent interaction and accommodates specific design requirements of individual stages. This provides a more nuanced approach that identifies similarities and differences in the design requirements of the stages of the customer journey.

\section{$<$ Please insert Table 5 about here $>$}

Third, we identify stage specific dimensions that do not reconcile with design characteristics found in SDS design frameworks. While we find a relatively high degree of proximity between the dimensions identified in our study and extant service classifications (see Table 5), we capture several additional dimensions that are not present in this extant work. These dimensions include: relationships with fellow patients; continuity of care; staff availability; food and beverage; indirect communication. At both the Inpatient Care and End-of-Life Care stages, we find that patients value establishing good relationships with fellow patients. This suggests that SDS should explicitly accommodate designs to capitalise on the benefits of a social environment. This issue has been previously reported in experience-centric and peopleintensive SDS (Zomerdijk and Voss, 2010; Verhoef et al., 2009). Whilst the importance of the availability of an adequate supply and selection of food and beverage has been noted previously (Fottler et al., 2006), we add that both the diversity and suitability of the food and beverages supplied matter. Suitability describes the patient's feeling that the type of food and drinks served is appropriate for his/her condition. Diversity refers to whether the patient feels that there is an appropriate variety in the food and drinks served. While service classifications emphasise staff (direct) communication, they fail to account for the role of other forms of communication: leaflets, letters, brochures, sign-posts, in shaping the patient experience. These omissions highlight the need to take a patient-centric perspective in order to surface all 
the key issues that emerge in the minds of patients (Lemke et al., 2011). Adopting a patientcentric perspective helps to provide a finer-grained and more precise specification of SDS design requirements.

\section{Implications for practice}

Adopting a patient-centric approach has important implications for the design, measurement and improvement of the SDS that supports the patient experience. This work emphasises the need to consider the healthcare journey to develop and manage the SDS from the patient's perspective. Delivering high quality experiences involves understanding how patients perceive their interactions with the healthcare system at all points in their journey, and incorporating these insights into SDS design requirements. Healthcare providers and policymakers need to pay attention to the specific requirements of the individual stages that collectively comprise the patient journey. This involves identifying the stages patients go through to get diagnosed, treated and cared for as well as capturing the issues that matter to them at each stage. More specifically, we propose five activities for managing SDS for the patient experience. We recommend that practitioners: (1) identify the nature of the journeys taken by patients suffering from different conditions and establish the main stages of each journey; (2) develop an understanding of the quality dimensions of the experience that matter most to patients during each stage of the journey; (3) monitor patients' perceptions about what works and what does not work at each stage; (4) identify and prioritise problematic areas that require operational improvements; (5) (re)design the SDS for an enhanced patient experience.

Furthermore, the dimensions of the conceptual framework can be used to build a practical tool for evaluating SDS design and patient experience quality. Raleigh et al. (2012) demonstrate the benefits of using standard measurement instruments that allow for 
meaningful comparisons of performance across several areas. This study provides evidence of what matters to cancer patients across the stages that comprise the journey. The results emphasise core and stage-specific dimensions that are critical patient experience quality. This provide a strong rationale for measuring experience quality at each stage of the journey and to account for the patient's end-to-end experience. This understanding can inform the creation of a straightforward and practical diagnostic and benchmarking tool for healthcare practitioners who seek to evaluate patient experience quality. We suggest that focusing on the journey informs the design and improvement of healthcare systems in a meaningful patientcentric way.

\section{Limitations and future research}

Future research could extend this work in several ways. First, the importance of experience quality dimensions at each stage need to be carefully examined using survey-based research methods in order to validate the findings. Second, the relative contribution of each dimension to an overall assessment of patient experience quality could be explored to identify critical design requirements. This would involve determining the relative weight of each dimension per stage. Third, follow-up work could investigate the cumulative effects of quality perceptions from one stage to another. This could include investigating the varying threshold of expectation given previous interactions and experience. Fourth, researchers could replicate this study across a range of service contexts to ascertain how the customer journey and the quality dimensions vary and illuminate contextual implications for SDS design. Fifth, while patient feedback in natural language form provides rich insights into patient perception, analysis of this data is resource intensive. Given advanced methods and algorithms for processing natural language, additional research is required to explore possibilities for automation through text analytics to facilitate SDS design and renewal. 
Finally, this study has several limitations. First, the 200 stories analysed do not constitute a representative sample of the cancer patient population. Second, the patient journey can be analysed at varying degrees of granularity and the identification of key stages is subject to interpretation. Each stage could arguably be decomposed into a series of lowerlevel episodes. Third, assurance of the factual occurrence of each story cannot be verified. It is important, however, to recall that experience quality involves perceptual feelings and judgments. Fourth, we were unable to determine the severity of the conditions that members of our sample were experiencing which could influence the patient's description of their journeys and associated perceptions of service quality.

\section{CONCLUSIONS}

As medical science continues to make substantial advances in improving treatments, similar effort is required by social scientists to contribute to the effective design and management of healthcare operations. This research emphasises the importance of deriving SDS design requirements from a customer-centric perspective contextualised by the stage of the customer journey. Whilst the journey stages and dimensions identified are specific to the healthcare context, we believe that theoretical and practical implications are more far reaching. The adoption of a customer-centric perspective, focused on experience quality dimensions across multiple journey stages, and using a multi-mode framework of interactions, highlights the inadequacy of existing SDS design frameworks. The granular view of the customer's experience affords the identification of similarity and difference in quality dimensions across the stages of the customer journey. This informs the specification of suitable design requirements to develop a SDS that facilitate the achievement of high-quality customer experiences. 


\section{REFERENCES}

Anderson, J.C., Rungtusanatham, M. and Schroeder, R.G. (1994), "A theory of quality management underlying the Deming management method", Academy of management Review, Vol. 19 No. 3, pp. 472-509.

Baig, A., Dua, A. and Riefberg, V. (2014), How US state governments can improve customer service. McKinsey \& Company.

Bate, P. and Robert, G. (2006), "Experience-based design: from redesigning the system around the patient to co-designing services with the patient ", BMJ Quality \& Safety, Vol. 15 No. 5, pp. 307-310.

Bitner, M.J., Ostrom, A.L. and Morgan, F.N. (2008), "Service blueprinting: a practical technique for service innovation", California management review, Vol. 50 No. 3, pp. 66-94.

Black, N. and Jenkinson, C. (2009), "Measuring patients' experiences and outcomes", $B M J$, Vol. 339 No. b2495, pp. 1-5.

Bowen, G.A. (2008), "Naturalistic inquiry and the saturation concept: a research note", Qualitative research, Vol. 8 No. 1, pp. 137-152.

Collier, D.A. and Meyer, S.M. (1998), "A service positioning matrix", International Journal of Operations \& Production Management, Vol. 18 No. 12, pp. 1223-1244.

Contiero, E., Ponsignon, F., Smart, P.A. and Vinelli, A. (2016), "Contingencies and characteristics of service recovery system design: Insights from retail banking", International Journal of Operations \& Production Management, Vol. 36 No. 11, pp. 1644-1667.

Cook, D.P., Goh, C.-H. and Chung, C.H. (1999), "Service Typologies: A State of the Art Survey", Production \& Operations Management, Vol. 8 No. 3, pp. 318-338.

Dagger, T.S., Sweeney, J.C. and Johnson, L.W. (2007), "A Hierarchical Model of Health Service Quality: Scale Development and Investigation of an Integrated Model", Journal of Service Research, Vol. 10 No. 2, pp. 123-142.

Danaher, T.S. and Gallan, A.S. (2016), "Service Research in Health Care Positively Impacting Lives", Journal of Service Research, Vol. 19 No. 4, pp. 433-437.

Darzi, L. (2008), High quality care for all: NHS Next Stage Review final report.

Dijkstra, L. and van der Bij, H. (2002), "Quality function deployment in healthcare", International Journal of Quality \& Reliability Management, Vol. 19 No. 1, pp. 67-89.

Drupsteen, J., Vaart, T.v.d. and Donk, D.P.v. (2013), "Integrative practices in hospitals and their impact on patient flow", International Journal of Operations \& Production Management, Vol. 33 No. 7, pp. 912-933.

Fottler, M.D., Dickson, D., Ford, R.C., Bradley, K. and Johnson, L. (2006), "Comparing hospital staff and patient perceptions of customer service: a pilot study utilizing survey and focus group data", Health Services Management Research, Vol. 19 No. 1, pp. 52-66.

Francis, R. (2013), Report of the Mid Staffordshire NHS Foundation Trust Public Inquiry.

Frei, F.X. (2007), "Breaking the Trade-Off Between Efficiency and Service", Harvard Business Review, Vol. 85 No. 3, pp. 93-101.

Garratt, A., Solheim, E. and Danielsen, K. (2008), National and cross-national surveys of patient experiences: a structured review. Oslo: Nasjonalt kunnskapssenter for helset jenesten.

Goodrich, J. and Cornwell, J. (2008), Seeing the person in the patient: the point of care review paper. The King's Fund. 
Greaves, F., Ramirez-Cano, D., Millett, C., Darzi, A. and Donaldson, L. (2013), "Harnessing the cloud of patient experience: using social media to detect poor quality healthcare", BMJ Qual Saf, Vol. 22 No. 3, pp. 251-5.

Gremler, D.D. (2004), "The Critical Incident Technique in Service Research", Journal of Service Research, Vol. 7 No. 1, pp. 65-89.

Grosios, K., Gahan, P.B. and Burbidge, J. (2010), "Overview of healthcare in the UK", The EPMA Journal, Vol. 1 No. 4, pp. 529-534.

Gruber, T. and Frugone, F. (2011), "Uncovering the desired qualities and behaviours of general practitioners (GPs) during medical (service recovery) encounters", Journal of Service Management, Vol. 22 No. 4, pp. 491-521.

Helkkula, A. (2011), "Characterising the concept of service experience", Journal of Service Management, Vol. 22 No. 3, pp. 367-389.

Henrique, D.B., Rentes, A.F., Godinho Filho, M. and Esposto, K.F. (2016), "A new value stream mapping approach for healthcare environments", Production Planning \& Control, Vol. 27 No. 1, pp. 24-48.

Ho Voon, B., Abdullah, F., Lee, N. and Kueh, K. (2014), "Developing a HospiSE scale for hospital service excellence", International Journal of Quality \& Reliability Management, Vol. 31 No. 3, pp. 261-280.

Homburg, C., Jozić, D. and Kuehnl, C. (2017), "Customer experience management: toward implementing an evolving marketing concept", Journal of the Academy of Marketing Science, Vol. 45 No. 3, pp. 377-401.

Johansson, P. and Olhager, J. (2004), "Industrial service profiling: Matching service offerings and processes", International Journal of Production Economics, Vol. 89 No. 3, pp. 309-320.

Johnston, R. and Kong, X. (2011), "The customer experience: a road-map for improvement", Managing Service Quality, Vol. 21 No. 1, pp. 5-24.

Keaveney, S.M. (1995), "Customer Switching Behavior in Service Industries: An Exploratory Study", Journal of Marketing, Vol. 59 No. 2, pp. 71-82.

Kranzbühler, A.M., Kleijnen, M.H., Morgan, R.E. and Teerling, M. (2017), "The Multilevel Nature of Customer Experience Research: An Integrative Review and Research Agenda", International Journal of Management Reviews, Vol. No., pp.

Lagrosen, Y., Bäckström, I. and Lagrosen, S. (2007), "Quality management and health: A double connection", International Journal of Quality \& Reliability Management, Vol. 24 No. 1, pp. 49-61.

Lee, H., Vlaev, I., King, D., Mayer, E., Darzi, A. and Dolan, P. (2013), "Subjective wellbeing and the measurement of quality in healthcare", Social Science \& Medicine, Vol. 99 No. 0, pp. 27-34.

Lemke, F., Clark, M. and Wilson, H. (2011), "Customer experience quality: an exploration in business and consumer contexts using repertory grid technique", Journal of the Academy of Marketing Science, Vol. 39 No. 6, pp. 846-869.

Lemon, K.N. and Verhoef, P.C. (2016), "Understanding customer experience throughout the customer journey", Journal of Marketing, Vol. 80 No. 6, pp. 69-96.

Machuca, J.A.D., Gonzalez-Zamora, M.M. and Aguilar-Escobar, V.G. (2007), "Service Operations Management research", Journal of Operations Management, Vol. 25 No. 3, pp. 585-603.

Manary, M.P., Boulding, W., Staelin, R. and Glickman, S.W. (2013), "The Patient Experience and Health Outcomes", New England Journal of Medicine, Vol. 368 No. 3, pp. 201-203.

Metters, R. and Vargas, V. (2000), "A typology of de-coupling strategies in mixed services", Journal of Operations Management, Vol. 18 No. 6, pp. 663-682. 
NICE (2012), Patient experience in adult NHS services.

Perreault, W. and Leigh, L. (1989), "Reliability of Nominal Based Data on Qualitative Judgements", Journal of Marketing Research, Vol. 26 No. May, pp. 86-97.

Ponsignon, F., Klaus, P. and Maull, R. (2015a), "Experience co-creation in financial services: an empirical exploration ", Journal of Service Management, Vol. 26 No. 2, pp. 295 320.

Ponsignon, F., Smart, A., Williams, M.D. and Hall, J. (2015b), "Healthcare experience quality: an empirical exploration using content analysis techniques", Journal of Service Management, Vol. 26 No. 3, pp. 460-485.

Ponsignon, F., Smart, P.A. and Maull, R.S. (2011), "Service delivery system design: characteristics and contingencies", International Journal of Operations \& Production Management, Vol. 31 No. 3, pp. 324-349.

Prakash, A. and Mohanty, R.P. (2013), "Understanding service quality", Production Planning \& Control, Vol. 24 No. 12, pp. 1050-1065.

Pullman, M.E. and Gross, M.A. (2004), "Ability of Experience Design Elements to Elicit Emotions and Loyalty Behaviors", Decision Sciences, Vol. 35 No. 3, pp. 551-578.

Raleigh, V.S., Frosini, F., Sizmur, S. and Graham, C. (2012), "Do some trusts deliver a consistently better experience for patients? An analysis of patient experience across acute care surveys in English NHS trusts", BMJ Qual Saf, Vol. 21 No., pp. 381-390.

Rawson, A., Duncan, E. and Jones, C. (2013), "The truth about customer experience", Harvard Business Review, Vol. 91 No. 9, pp. 90-98.

RCN (2013), Content analysis of 'Patient Opinion' website stories about nurse attitudes and behaviours London: RCN

Rich, N. and Piercy, N. (2013), "Losing patients: a systems view on healthcare improvement", Production Planning \& Control, Vol. 24 No. 10-11, pp. 962-975.

Roth, A.V. and Menor, L.J. (2003), "Insights into service operations management: a research agenda", Production \& Operations Management, Vol. 12 No. 2, pp. 145-164.

Russell, R.S., Johnson, D.M. and White, S.W. (2015), "Patient perceptions of quality: analyzing patient satisfaction surveys", International Journal of Operations \& Production Management, Vol. 35 No. 8, pp. 1158-1181.

Ryan, M., Kinghorn, P., Entwistle, V.A. and Francis, J.J. (2014), "Valuing patients' experiences of healthcare processes: Towards broader applications of existing methods", Social Science \& Medicine, Vol. 106 No. 0, pp. 194-203.

Safizadeh, M.H., Field, J.M. and Ritzman, L.P. (2003), "An empirical analysis of financial services processes with a front-office or back-office orientation", Journal of Operations Management, Vol. 21 No. 5, pp. 557-576.

Sampson, S.E. (2012), "Visualizing Service Operations", Journal of Service Research, Vol. 15 No. 2, pp. 182-198.

Sampson, S.E. and Froehle, C.M. (2006), "Foundations and Implications of a Proposed Unified Services Theory", Production \& Operations Management, Vol. 15 No. 2, pp. 329-343.

Silvestro, R. (1999), "Positioning services along the volume-variety diagonal", International Journal of Operations \& Production Management, Vol. 19 No. 3/4, pp. 399-420.

Sousa, R., Amorim, M., Pinto, G.M. and Magalhães, A. (2016), "Multi-channel deployment: a methodology for the design of multi-channel service processes", Production Planning \& Control, Vol. 27 No. 4, pp. 312-327.

Stanworth, J.O. (2012), "Deep supply relationships: influencing outcomes by managing supply service quality", Production Planning \& Control, Vol. 23 No. 7, pp. 541-552. 
Stuart, F.I. and Tax, S. (2004), "Toward an integrative approach to designing service experiences: Lessons learned from the theatre", Journal of Operations Management, Vol. 22 No. 6, pp. 609-627.

Tax, S.S., McCutcheon, D. and Wilkinson, I.F. (2013), "The service delivery network (SDN) a customer-centric perspective of the customer journey", Journal of Service Research, Vol. 16 No. 4, pp. 454-470.

Tsianakas, V., Robert, G., Maben, J., Richardson, A., Dale, C., Griffin, M. and Wiseman, T. (2012), "Implementing patient-centred cancer care: using experience-based co-design to improve patient experience in breast and lung cancer services", Supportive Care in Cancer, Vol. 20 No. 11, pp. 2639-47.

Ulbrich, S., Troitzsch, H., van den Anker, F., Plüss, A. and Huber, C. (2011), "How teams in networked organisations develop collaborative capability: processes, critical incidents and success factors", Production Planning \& Control, Vol. 22 No. 5-6, pp. 488-500.

van Schoten, S., de Blok, C., Spreeuwenberg, P., Groenewegen, P. and Wagner, C. (2016), "The EFQM Model as a framework for total quality management in healthcare: Results of a longitudinal quantitative study", International Journal of Operations \& Production Management, Vol. 36 No. 8, pp. 901-922.

Verhoef, P.C., Lemon, K.N., Parasuraman, A., Roggeveen, A., Tsiros, M. and Schlesinger, L.A. (2009), "Customer Experience Creation: Determinants, Dynamics and Management Strategies", Journal of Retailing, Vol. 85 No. 1, pp. 31-41.

Verma, R. and Thompson, G.M. (1999), "Managing service operations based on customer preferences", International Journal of Operations \& Production Management, Vol. 19 No. 9, pp. 891-908.

Vissers, J.M., Bertrand, J. and De Vries, G. (2001), "A framework for production control in health care organizations", Production Planning \& Control, Vol. 12 No. 6, pp. 591604.

Voss, C.A., Roth, A. and Chase, R.B. (2008), "Experience, Service Operations Strategy, and Services as Destinations: Foundations and Exploratory Investigation", Production and Operations Management, Vol. 17 No. 3, pp. 247-266.

Wang, T., Guinet, A., Belaidi, A. and Besombes, B. (2009), "Modelling and simulation of emergency services with ARIS and Arena. Case study: the emergency department of Saint Joseph and Saint Luc Hospital", Production Planning and Control, Vol. 20 No. 6, pp. 484-495.

WHO (2016), WHO Framework on Integrated People-Centered Health Services.

Wisniewski, M. and Wisniewski, H. (2005), "Measuring service quality in a hospital colposcopy clinic", International Journal of Health Care Quality Assurance, Vol. 18 No. 3, pp. 217-228.

Zomerdijk, L.G. and Voss, C.A. (2010), "Service Design for Experience-Centric Services", Journal of Service Research, Vol. 13 No. 1, pp. 67-82. 
Table 1: Stages of the patient journey

\begin{tabular}{|c|c|c|c|c|}
\hline Stage & $\begin{array}{c}\mathrm{N} \text { of } \\
\text { attributes }\end{array}$ & $\begin{array}{c}\% \text { of } \\
\text { attributes }\end{array}$ & $\begin{array}{c}\mathrm{N} \text { of } \\
\text { stories* }\end{array}$ & $\begin{array}{c}\% \text { of } \\
\text { stories* }\end{array}$ \\
\hline Receive Diagnosis & 223 & $18 \%$ & 60 & $30 \%$ \\
\hline Inpatient Care & 558 & $46 \%$ & 107 & $54 \%$ \\
\hline Outpatient Care & 221 & $18 \%$ & 55 & $28 \%$ \\
\hline Post-Treatment Care & 73 & $7 \%$ & 34 & $17 \%$ \\
\hline End-of-Life Care & 132 & $11 \%$ & 22 & $11 \%$ \\
\hline 8 & 1207 & $100 \%$ & & \\
\hline
\end{tabular}

*Sums greater than 200 and 100\% due to multiple attributes present per stage in any one story. This should be interpreted as, for example, experience attributes within the Receive Diagnosis stage of the patient journey were found in $30 \%$ of stories. 
Table 2: Definitions of experience quality dimensions

\begin{tabular}{|c|c|c|}
\hline $\begin{array}{c}\text { Mode of } \\
\text { Interaction }\end{array}$ & Dimension & Definition \\
\hline \multirow{8}{*}{ Direct Interactions } & Attitudes and behaviours & Staff are interested in and care for patients. \\
\hline & Competence & Staff possess and apply the required knowledge and expertise \\
\hline & Communication & Staff communicate (e.g. face-to-face or telephone) effectively with patients. \\
\hline & Personalisation & Staff adapt care services to suit patient needs. \\
\hline & Efficiency & Staff value and use patients' time efficiently. \\
\hline & Availability & Staff are easily found and accessed by patients. \\
\hline & $\begin{array}{l}\text { Relationships with } \\
\text { fellow patients }\end{array}$ & erience of some patients impact the experience of others. \\
\hline & Continuity of care & Staff builds and maintains patient relationships. \\
\hline \multirow{7}{*}{ Indirect Interactions } & Procedures and processes & The provider operates efficient and effective internal processes. \\
\hline & Premises and facilities & The physical environment is pleasant, appealing and appropriate. \\
\hline & Timeliness & The provider values and uses patients' time in the facilities efficiently. \\
\hline & Food and beverage & The supply and selection of food and drinks. \\
\hline & Communication & Communication between the patient and the provider is effective. \\
\hline & Accessibility & Premises and facilities are easily accessible. \\
\hline & Service variety / choice & The range of care services offered. \\
\hline \multirow{2}{*}{ Independent Activity } & Timeliness & The provider values and uses patients' time outside the facilities efficiently. \\
\hline & Speed & The speed of a particular stage in the journey. \\
\hline
\end{tabular}


Table 3: Experience Quality Dimensions per Journey Stage

\begin{tabular}{|c|c|c|c|c|c|c|c|c|c|c|c|c|c|c|c|c|c|c|c|c|}
\hline \multirow{2}{*}{ Dimensions / Stages } & \multicolumn{4}{|c|}{ Receive Diagnosis } & \multicolumn{4}{|c|}{ Inpatient Care } & \multicolumn{4}{|c|}{ Outpatient Care } & \multicolumn{4}{|c|}{ Post-Treatment Care } & \multicolumn{4}{|c|}{ End-of-Life Care } \\
\hline & $\mathbf{N}$ & $\%$ & $\mathbf{S}^{*}$ & $\%$ & $\mathbf{N}$ & $\%$ & $\mathbf{S}^{*}$ & $\%$ & $\mathbf{N}$ & $\%$ & $\mathbf{S}^{*}$ & $\%$ & $\mathbf{N}$ & $\%$ & $\mathbf{S}^{*}$ & $\%$ & $\mathbf{N}$ & $\%$ & $S^{*}$ & $\%$ \\
\hline \multicolumn{21}{|l|}{ Direct Interactions } \\
\hline Attitudes and behaviours & 64 & $29 \%$ & 28 & $47 \%$ & 240 & $43 \%$ & 78 & $73 \%$ & 95 & $43 \%$ & 37 & $67 \%$ & 17 & $23 \%$ & 11 & $32 \%$ & 64 & $48 \%$ & 20 & $91 \%$ \\
\hline Communication & 26 & $12 \%$ & 20 & $33 \%$ & 44 & $8 \%$ & 37 & $35 \%$ & 17 & $8 \%$ & 15 & $27 \%$ & 4 & $5 \%$ & 4 & $12 \%$ & 10 & $8 \%$ & 8 & $36 \%$ \\
\hline Personalisation & 16 & $7 \%$ & 14 & $23 \%$ & 47 & $8 \%$ & 38 & $36 \%$ & 16 & $7 \%$ & 12 & $22 \%$ & 8 & $11 \%$ & 7 & $21 \%$ & 18 & $13 \%$ & 13 & $59 \%$ \\
\hline Competence & 20 & $9 \%$ & 18 & $30 \%$ & 40 & $7 \%$ & 28 & $26 \%$ & 13 & $6 \%$ & 11 & $20 \%$ & 10 & $14 \%$ & 8 & $24 \%$ & 6 & $5 \%$ & 6 & $27 \%$ \\
\hline Staff efficiency & 7 & $3 \%$ & 7 & $12 \%$ & & & & & & & & & & & & & & & & \\
\hline Staff availability & & & & & 21 & $4 \%$ & 20 & $19 \%$ & & & & & & & & & 4 & $3 \%$ & 4 & $18 \%$ \\
\hline Relationship with patients & & & & & 18 & $3 \%$ & 16 & $15 \%$ & & & & & & & & & 5 & $4 \%$ & 4 & $18 \%$ \\
\hline Continuity of care & & & & & & & & & & & & & 4 & $5 \%$ & 4 & $12 \%$ & & & & \\
\hline \multicolumn{21}{|l|}{ Indirect Interactions } \\
\hline Premises and facilities & 13 & $6 \%$ & 7 & $12 \%$ & 55 & $10 \%$ & 31 & $29 \%$ & 20 & $9 \%$ & 11 & $20 \%$ & 4 & $5 \%$ & 4 & $12 \%$ & 9 & $7 \%$ & 7 & $32 \%$ \\
\hline Procedures and processes & 18 & $8 \%$ & 15 & $25 \%$ & 42 & $8 \%$ & 31 & $29 \%$ & 11 & $5 \%$ & 10 & $18 \%$ & 16 & $22 \%$ & 13 & $38 \%$ & 9 & $7 \%$ & 7 & $32 \%$ \\
\hline Communication & 21 & $9 \%$ & 14 & $23 \%$ & 22 & $4 \%$ & 17 & $16 \%$ & 10 & $5 \%$ & 8 & $15 \%$ & 4 & $5 \%$ & 4 & $12 \%$ & 4 & $3 \%$ & 3 & $14 \%$ \\
\hline Timeliness & 8 & $4 \%$ & 8 & $13 \%$ & & & & & 12 & $5 \%$ & 12 & $22 \%$ & & & & & & & & \\
\hline Food and beverages & & & & & 29 & $5 \%$ & 22 & $21 \%$ & & & & & & & & & & & & \\
\hline Accessibility & & & & & & & & & 22 & $10 \%$ & 17 & $31 \%$ & & & & & & & & \\
\hline \multicolumn{21}{|l|}{ Independent Activity } \\
\hline Speed & 11 & $5 \%$ & 11 & $18 \%$ & & & & & & & & & & & & & & & & \\
\hline Timeliness & 19 & $9 \%$ & 15 & $25 \%$ & & & & & 5 & $2 \%$ & 6 & $11 \%$ & 6 & $8 \%$ & 4 & $12 \%$ & & & & \\
\hline Total & 223 & & 60 & & 558 & & 107 & & 221 & & 55 & & 73 & & 34 & 8 & 132 & & 22 & \\
\hline
\end{tabular}

$\mathrm{N}$ : number of attributes; S: number of stories.

*Sum greater than actual total due to multiple attributes identified per stage in any one story. 
Table 4: Common experience quality dimensions across the patient journey

\begin{tabular}{lcccc} 
& \multicolumn{2}{c}{ Attributes } & \multicolumn{2}{c}{ Stories } \\
& N & $\%$ & S & $\%$ \\
\hline Direct Interactions & & & & \\
Attitudes and behaviours & 480 & $39,8 \%$ & 159 & $79,5 \%$ \\
Personalisation & 105 & $8,7 \%$ & 82 & $41,0 \%$ \\
Communication & 101 & $8,4 \%$ & 79 & $39,5 \%$ \\
Competence & 89 & $7,4 \%$ & 66 & $33,0 \%$ \\
& & & & \\
Indirect Interactions & & & & \\
Premises and facilities & 101 & $8,4 \%$ & 57 & $28,5 \%$ \\
Procedures and processes & 96 & $8,0 \%$ & 58 & $29,0 \%$ \\
Communication & 61 & $5,1 \%$ & 43 & $21,5 \%$ \\
\hline
\end{tabular}


Table 5: Reconciling patient and provider perspective on SDS design

\begin{tabular}{|c|c|c|}
\hline & $\begin{array}{l}\text { tient experience } \\
\text { dimensions }\end{array}$ & $\begin{array}{c}\text { SDS Design } \\
\text { characteristics* }\end{array}$ \\
\hline & Staff attitudes and behaviours & People-focus \\
\hline & Competence & $\begin{array}{l}\text { Diagnostic skills } \\
\text { Technical skills }\end{array}$ \\
\hline & Direct communication & Interpersonal skills \\
\hline dimensions & Personalisation & $\begin{array}{c}\text { Customisation } \\
\text { Employee discretion }\end{array}$ \\
\hline & Procedures and processes & Formality \\
\hline & Premises and facilities & Facilities layout \\
\hline & Indirect communication & Non applicable \\
\hline \multirow{7}{*}{$\begin{array}{l}\text { Stage-specific } \\
\text { dimensions }\end{array}$} & Accessibility & Facilities location \\
\hline & Service variety / choice & Range of services \\
\hline & $\begin{array}{l}\text { Staff efficiency, speed, } \\
\text { timeliness }\end{array}$ & Efficiency \\
\hline & Continuity of care & Non applicable \\
\hline & Staff availability & Non applicable \\
\hline & $\begin{array}{l}\text { Relationships with } \\
\text { fellow patients }\end{array}$ & Non applicable \\
\hline & Food and beverage & Non applicable \\
\hline
\end{tabular}

*based on Cook et al. (1999), Johansson and Olhager (2004) and Ponsignon et al. (2011) 
Appendix - Supporting quotes for experience quality dimensions

Dimension

Supporting Evidence

Code

\begin{tabular}{|c|c|c|c|}
\hline \multirow{8}{*}{ 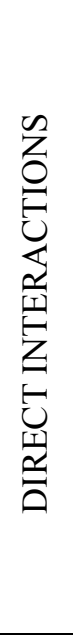 } & Attitudes and behaviours & $\begin{array}{l}\text { "The entire team working with cancer in-patients from dinner ladies to top consultants were kind, } \\
\text { caring and professional" (Story 4) }\end{array}$ & ATT \\
\hline & Competence & $\begin{array}{l}\text { "They should admit to not knowing answers to your questions. I had researched my condition and } \\
\text { knew of the chemo treatment that they had dismissed" (Story 7) }\end{array}$ & $\mathrm{COM}$ \\
\hline & Communication & "They kept me well informed, explaining all procedures in detail" (Story 15) & DCO \\
\hline & Personalisation & "They made every effort to accommodate my wishes providing my life wasn't in danger" (Story 31) & PER \\
\hline & Staff efficiency & 'They require replacing with staff who are rapid in their work at all times'. (Story 38) & STE \\
\hline & Staff availability & $\begin{array}{l}\text { "Trying to get hold of a consultant was incredibly frustrating, as nobody knows what time they are } \\
\text { going to turn up" (Story 45) }\end{array}$ & AVA \\
\hline & $\begin{array}{l}\text { Relationships with } \\
\text { fellow patients }\end{array}$ & $\begin{array}{l}\text { "The other patients in the ward were the biggest problem, it was like a zoo. There was no division } \\
\text { between the aggressive patients, often alcoholics from the nearby green, who caused havoc for the } \\
\text { patients more seriously ill" (Story 52) }\end{array}$ & RFP \\
\hline & Continuity of care & $\begin{array}{l}\text { "I have follow-up appointments every three months. To date I have seen } 17 \text { different doctors, with } \\
\text { whom I am supposed to trust my life. I have requested several times to see the same doctor at each } \\
\text { appointment but apparently that is not possible" (Story 58) }\end{array}$ & RST \\
\hline \multirow{8}{*}{ 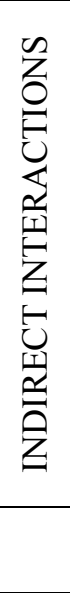 } & Procedures and processes & "The cervical cancer service is well organised" (Story 65) & PRP \\
\hline & Premises and facilities & $\begin{array}{l}\text { "The surroundings are clean, fresh and can only be described as being of a standard akin to a top } \\
\text { class hotel" (Story } 84 \text { ) }\end{array}$ & PRE \\
\hline & Timeliness & "I liked the very short waiting time in the clinic" (Story 98) & TIM \\
\hline & Food and beverage & $\begin{array}{l}\text { "The choices on the menu are the same every day, how boring!" (Story 111) } \\
\text { "I was admitted for surgery. Having previously been given a booklet detailing the operation and }\end{array}$ & FAB \\
\hline & Communication & $\begin{array}{l}\text { everything relating to the treatment, I was well prepared for my stay. This booklet was of great use" } \\
\text { (Story } 130 \text { ) }\end{array}$ & ICO \\
\hline & Accessibility & $\begin{array}{l}\text { "The car park is very busy and can make you late for appointments, which adds to an already stressful } \\
\text { situation" (Story 142) }\end{array}$ & $\mathrm{ACC}$ \\
\hline & Service variety / choice & $\begin{array}{l}\text { "We were offered bereavement counselling; it was very helpful and helped me prepare for what } \\
\text { became inevitable" (Story 176) }\end{array}$ & SVC \\
\hline & $\begin{array}{l}\text { Timeliness } \\
\text { Speed }\end{array}$ & $\begin{array}{l}\text { "I got the results of the biopsy in two days, so no stressful waiting around at home" (Story 182) } \\
\text { "The whole process of getting diagnosed needs speeding up" (Story 199) }\end{array}$ & $\begin{array}{l}\text { TIMI } \\
\text { SPE }\end{array}$ \\
\hline
\end{tabular}




\section{Page 39 of 39}

International Journal of Quality \& Reliability Management 